\title{
Role of sociologists and cultural anthropologists in the development, adaptation and transfer of new agricultural technologies
}

\author{
D. B. W. M. VAN DUSSELDORP \& L. BOX
}

Department of Sociology of Rural Development, Wageningen Agricultural University, P.O. Box 8130, NL 6700 EW Wageningen, Netherlands

Received 14 November 1989; accepted 13 August 1990

\begin{abstract}
Despite the amount of discussion on the role of sociology and anthropology in agricultural research over the last two decades, the number of sociologists in agricultural research stations is still remarkably low. On the basis of recent literature and two research projects in the Dominican Republic and the Philippines, the potential roles and placement of sociologists in agricultural research are elaborated. The roles discussed are those of trainer/sensitizer, provider of methods, go-between/translator, monitor/evaluator, assessor of social impact, analyser of the creation and use of indigenous knowledge, accommodator, scout, developer of group technologies, and analyser of the functioning of agricultural research.
\end{abstract}

Keywords: sociology and anthropology, agricultural research institutes, farmers/indigenous knowledge, adaptation, agricultural technology

\section{Introduction}

The role of the sociologist and cultural anthropologist in agricultural research has been the subject of discussion since de Schlippe (1956). However, since the green revolution, interest in the contribution they have to make has increased, although at present their status with agricultural research establishments is as best as junior partners (Kruiter, 1988) and, more often than not, they are not represented at all.

We use the term sociologist in this paper to refer to both sociologist and cultural anthropologist and avoid using the notion of 'social scientist' since for many authors this would also include economists (Ruttan, 1982).

Recently, new approaches such as on-farm research, adaptive research, and farming systems research, have become fashionable in agricultural research. Such approaches take place, at least in part, outside the bounds of the agricultural research station and this has allowed more scope for the involvement of sociologists.

We intend in this paper to elaborate further upon this theme, namely, the existing and potential roles for sociologists in agricultural research, a theme which has been explored previously by several authors (among others van Dusseldorp, 1977; Ruttan, 1982; Horton, 1984; Rhoades, 1984; Jones \& Wallace, 1986; Sutherland, 1988). 
Our discussion is based upon the existing literature, our own experience and on the outcome of two research projects addressed specifically to the theme. Attention is also given to the placement or position from which the sociologist could perform these roles best.

Sociology and cultural anthropology study the processes and patterns of social action and interrelationships and the institutional forms of organization as well as the social and cultural constraints on individual and group behaviour.

The main functions of such disciplines in agricultural research are:

1. To assess the consequences that new animal and plant breeds and production techniques might have on human behaviour and the functioning of agrarian societies.

2. To assess, through an examination of the social context in which agricultural production takes place and the local and indigenous forms of knowledge available, which kind of innovations may be beneficial for rural society in general and for the small cultivator in particular.

In carrying out these functions successfully the sociologist is involved in several different roles that constitute the focus of this paper (see Table 1 for an overview).

\section{Potential roles and positions of sociologists}

\section{Trainer and sensitizer}

It must be emphasized at the outset, that it is not so much the employment of sociologists in agricultural research stations that is important, but that social aspects are taken into consideration during the development of new agricultural technologies. This can best be carried out by persons equipped with the appropriate knowledge and methods of sociology at their fingertips. Perhaps the most efficient way to do this is to make sure that agricultural researchers become sufficiently acquainted during their training with some readily applicable sociological concepts and methods.

Table 1. Placement of sociologists in agricultural research in relation to their potential roles in international and national agricultural and non-agricultural research institues. $x \times=$ best position, $\times=$ good position, $-=$ poor position, $0=$ not likely.

\begin{tabular}{llll}
\hline Role sociologist & International & National/regional & Non-agricultural \\
Trainer/Sensitizer & $\times$ & $\circ$ & \\
Provider of methods & $\times$ & $\circ$ & $\times$ \\
Go-between/translator & $\times$ & $\times \times$ & $\times$ \\
Monitor/evaluator & $\times$ & $\times \times$ & $\times$ \\
Assessor Social Impact & $\times$ & $\times \times$ & $\times$ \\
Analyser of indigenous knowledge & $\times$ & $\times \times$ & $\times$ \\
Accommodator & $\times$ & $\times \times$ & $\times$ \\
Scout & $\times \times$ & $\times$ & $\times$ \\
Developer of group technology & $\times$ & - & $\times \times$ \\
Analyser of agr. research & - & & $\times$ \\
\hline
\end{tabular}


They must also be taught, during their field experience, to be observant of the sociological aspects of their work, not only those that relate specifically to their own disciplines. At the same time they should be prepared to bear in mind the social consequences of introducing new findings. Also important is the need to realize their own limitation in the field of sociological observation and analysis, and to know which sociological observations they can make for themselves, and in which situations they should invoke the help of sociologists. This means that sociologists who are willing and capable of providing this assistance, must be readily available.

In theory, the best place to start this sensitizing process is in the universities and other institutions responsible for education and training. Courses on the sociological aspects of technological development in agriculture ought to be included in the curriculum. Another possibility is to ensure that post graduate courses are available which cover the appropriate topics and themes, such as the International Course on Development Oriented Research in Agriculture (ICRA) presently offered at Wageningen. Finally these subjects could also be introduced in the in-service training of research stations and through the seminars they hold.

The most logical position for the sociologist performing the role of sensitizer or trainer would be in universities or social research institutes. However, it is important that sociologists performing this role are at least familiar with the way agricultural scientists work and how agricultural research stations operate.

\section{Provider of methods}

The sociologist has a contribution to make in the field of methods for research. How to obtain relevant information from farmers via open and semi-structured interviews and unobtrusive methods of observations is not only of great use to sociologists (Webb et al., 1966).

For gathering quantitative information survey techniques, employing structured and pre-coded interviews, are appropriate. However, there is a tendency to apply this method too early, resulting in a massive amount of data that has little or no relevance. Only when sufficient insight has been achieved in a specific situation does it become possible to ask the relevant questions. To obtain such detailed qualitative insights into sociological processes at the local level the case study approach used by cultural anthropologists would be valuable, but such a method demands a considerable input of time and may be too time consuming for use in the context of agricultural research. The research programmes to investigate the role of sociology/cultural anthropology in the Dominican Republic and the Philippines, developed a new type of case study approach, the so-called 'diagnostic case study' (Box, 1988a; Doorman, 1989). This consists of carrying out three or four interrelated in-depth interviews, starting with open ended sessions and ending with interviews of a semistructured kind. Such interviews must be combined with observations in the field and therefore need to take place over a two to three week period. The importance of case studies in farmer oriented agricultural research is also emphasized by Polak (1986) and by Maxwell (1986), who likewise propose the case study method as a useful and cost-effective addition to the range of research tools used in multi- 
disciplinary farming systems research. This type of case study is essential before beginning large scale surveys.

Of course, the sociologist, as a provider of methods, can be located outside the agricultural research station. But when it is a question of developing methods relevant for and specific to agricultural research, he would be more appropriately and effectively located within international research institutes.

\section{Go-between/translator}

At present, the flow of information between the knowledge systems of farmers, extension officers and researchers is very limited. One of the reasons for this is the bias that occurs in the perception of a situation due to the different backgrounds or '(sub) cultures' from which the various actors come (Chambers, 1983). This can result in a different emphasis or identification of what constitutes a problem for research as was the case, for example, in the Dominican Republic, where farmers had a different hierarchy of problems related to cassava production than that of the research station (Box, 1988a). This means that, despite the vast and useful literature already existing within sociology and political economy on modes of production, there is still a considerable need for sociologists in the agricultural research process to collect detailed information on the social and socio-economic functioning of agricultural production systems in their particular social context. It is essential for agricultural research to produce results that are useful to farmers and that are consonant with the way farmers see their environment. To do this, an insight into the farmer's frame of reference, knowledge, and of how he or she uses this in the production process is indispensable.

By carrying out research of such matters in the field, the sociologist is in an ideal position to provide the conceptual frameworks to help the other scientists involved in agricultural research to understand the farmers' point of view and, vice versa, to give farmers valuable information on the actual sociological and biological functioning of farming and cropping systems. To carry out such applied research the sociologist is best placed within the agricultural research institute and can most adequately play the role of go-between from this position.

It is also important for the wealth of information presently stored in 'theoretical' sociological and cultural anthropological studies to be systematized and translated in such a way that it becomes available, comprehensible and useful for agricultural scientists. This makes it also possible to make diachronic analyses of the development of agricultural production systems. Sociologists involved in such work would naturally require an understanding of agricultural research though they may not feel themselves to be most appropriately based within such agricultural institutes.

\section{Monitor and evaluator}

Another function best performed by the sociologist is that of monitoring and evaluating, ex post facto, the consequences that new technologies have on existing production systems and their social context. 
Some of the dysfunctional aspects of the green revolution were made evident by sociologists working in this role. They showed, for example, the growing inequity in and between agricultural regions that resulted from this revolution. The results were sometimes broadcast with a zeal that was rather one-sided and that failed to address, among other things, what would have happened should the new high yielding varieties not have been generated by agricultural research. Although one would not wish to deny that it is the sociologists' moral obligation and role to identify and communicate the social and political consequences of new technological developments, this places them also under the obligation to perform this role in a responsible manner. One might question whether they have always done so. One thing is certain, the moralistic and political stance taken by many sociologists, even though not always in the extreme, as by Feder (1983) in his book 'Perverse development', has not made their entry into agricultural research circles any easier.

But the reality remains. Many of the results of agricultural research have profound consequences for the socio-economically weaker sections of societies. A few examples illustrate this. The development of a new sugarcane variety in the Cauca valley of Columbia, that keeps its sugar content at a high level for a longer period when it is ripe for harvesting, made it possible to extend the period of harvesting. This can be of importance when there is a chronic shortage of labour during harvesting periods. In the case of Columbia, it enabled plantation owners to break the strikes for a rise in pay by the poor and badly organized plantation workers. In Malaysia, the rubber research station of the plantation owners was instructed to develop a tree that could produce the same amount of latex with a considerable lower intensity of tapping. This was prompted by the assumption that the rual labour supply would diminish as a result of higher wages in other sectors of the economy, which could have endangered the future position of Malaysian rubber on the world market. It was clear from the beginning that the development of such a variety would lead to the expulsion of part of the labour force, in this case, mostly female labourers. The development of a more efficient threshing machine in the Philippines was beneficial for the rice growers, but not for the village poor who lost the addition to their meagre income that was obtained from gleaning the grain that was spilled. In the Dominican Republic, however, introducing the same type of new technology did not produce such a consequence (Box, 1988b).

It is often assumed that the introduction of new varieties affects the position of women, for example, in the harvesting of the crop. Field research in the Philippines did not find any direct correlation (Polak \& Acena, 1985). When such an expulsion did take place, it was the consequence of mechanization that, in itself, was not directly correlated to the introduction of new varieties. It thus became evident that cultural values play an important role in the employment or dismissal of female labour.

These examples make it clear that making quick general statements or assuming simple correlations between the introduction of new technologies and social change is not justifiable. The consequences of their introduction and the social mechanisms involved must be closely examined. The negative side-effects can then be identified and ways of mitigating them investigated. 
However, if sociologists are only employed in ex post facto evaluation, it is rather late in the day to come with measures that might mitigate the unwelcomed side effects of new agricultural technology.

Agricultural research and the implementation of its results in the field is a heuristic process and perhaps one of the most important contributions the sociologist can make is to follow this process throughout and ensure that sociological findings are integrated in time. Their research is certainly facilitated by, and maybe their contributions are more valuable, when they are an integral part of the research teams and placed like other members within research institutes. Their position is always a delicate one and this is especially the case where negative side effects are identified and where agricultural researchers have a rather narrow perception of their mandate.

\section{Assessor of social impact}

As mentioned, it is most common for sociologists to be involved in ex post facto evaluation. However, it is far more effective for them to be involved in an evaluation ex ante. In other words, for them to make an assessment of the likely impact and consequences of technology to be introduced in a specific environment, for instance a specific farming system, before the event. When the assessment of social impact (Finsterbusch \& Wolf, 1981) as a task for agricultural research stations was discussed in some of the institutes of the Consultative Group on International Agricultural Research (CGIAR), the objection was several times raised that this kind of activity entails the danger of institutes becoming involved in matters of policy that are outside their mandate. During one such discussion it became clear that the development of a new bean variety in South America could lead to small farmers being ousted from the production of beans for the market, from which they got a considerable part of their income. It was surprising to hear the breeder of this variety state that this was not his business, that he was paid to develop higher yielding bean varieties and that was all. Fortunately many of his colleagues held a different point of view.

One has to accept that it is not for the agricultural stations, or their researchers, to make the final decision on whether potential varieties should be developed. However, if social impact studies indicate that some dysfunctional effects can be expected for certain groups in a society, this must be communicated. Just as the manufacturers of medicines are obliged to indicate the potential side effects of their products for their users, it is likewise incumbent on research stations to give an indication of the potential side effects, positive and negative, that new technologies might have when introduced in a specific socio-economic context. It is then the responsibility of politicians and administrators to decide whether any dysfunctional effects are acceptable or not.

This problem becomes pressing in Africa, for example, where innovations in the agricultural production process are seen as the best instruments for increasing agricultural production without simultaneously having to increase the price of food commodities. However, at least in the first period of their introduction, such innovations will often affect the small farmers in an adverse way (Mellor \& Ahmed, 
1988). In this case, it is clearly a matter for policy makers at the higher levels to make the final decisions when it comes to the allocation of funds for the development of new technologies for agricultural production, and their introduction.

Recently, the need to include an assessment of the ecological consequences in impact studies has become painfully evident in Europe, where agricultural production has become an important factor in the deterioration of the environment. This leaves open for discussion the whole question of whether the ethical responsibility of researchers does not go beyond that of simply indicating the possible socioeconomic and ecological side effects, and leaving the responsibility for the allocation of funds for developing new technologies to administrators or politicians. It seems a moral obligation for agricultural researchers to get more involved, if only in an advisory role, in the decision making process regarding the future course of agricultural research.

The impression is that, in the past, those responsible for policy making in research stations too often hide behind their mandates. Researchers themselves were often so involved in proving that they were able to solve crucial technical problems in the field of food production that they were either unable or unwilling to consider the social consequences of their work. It would, however, do international agricultural research institutes an injustice if such observations were to give the impression that they were completely insensitive to the socio-economic and ecological consequences of their products. There have been various changes in the mandates of these institutes. Attention has shifted from maximal production techniques to production techniques with lower input levels and less risk. Recently, IRRI had to shift its attention from irrigated areas to less advantageous regions. Despite this, social aspects, on the whole, get step-motherly treatment. In a recent document of the Technical Advisory Committee of the Consultative Group on International Research (TAC/CGIAR, 1989) which dealt with the problems of sustainability, it was surprising and lamentable that so little attention was paid to the social aspects.

The main point to be made is that although social impact analysis is a relatively new field, and one which sociologists have entered somewhat hesitantly, it is nevertheless a field which could provide important information for policy making in agricultural research and is one in which sociologists have an important contribution to make. One reason of their hesitation is that at present there are only a limited number of social theories that are robust enough (Scott $\&$ Shore, 1979) to make long term predictions. Some caution is therefore necessary but this should not become an argument to refrain completely from efforts to make social impact assessments of new technologies. On the contrary, such studies will help to build the appropriate theories.

In assessing the potential effects of new technology sociologists need to be stationed in agricultural research centres. Only in that way, and providing they have open communication with colleagues in the other disciplines, they can properly inform themselves of the characteristics of any new, or to be developed, technology.

It should be recognized that the outcome of social impact studies made by the research stations, may themselves lead within such stations to a dysfunctional social impact. The bearer of unpleasant news has always been in a delicate position and 
this is particularly the case if he is the junior partner.

\section{Analysers of indigenous knowledge}

It is vital for agricultural researchers to be aware of the availability and importance of indigenous knowledge and the way it is generated and used by the farmers, often through experimentation in their own fields. It is only in the last decade that explicit attention has been given to the farmer as the creator of new knowledge. This is partly due to the fact that cultural anthropologists in the past have tended to describe small communities as rather static. The image of the farmer, and in particular the small farmer, as 'traditional', following only age-old production processes, is now fading away (Brokenshaw et al., 1980). Despite this, in many research stations and extension services in developing countries, the idea persists that the monopoly of superior knowledge with regard to agricultural production lies within their stations and related agencies. This is partly due to the social values to be found in the administrative system.

By making agricultural scientists aware of farmers as creators of new technologies in their own right, a foundation is laid for a fruitful dialogue between the experimenting scientist and the experimenting farmer (Box, 1989). The sociologist has an important role to play in analysing how indigenous knowledge is created and used within a specific social context, and in mediating his insights and facilitating an understanding between farmers, extension officers and scientists. Such a role can, be performed as well inside as outside agricultural stations.

\section{Accommodator}

It is not enough for the sociologists to indicate the social consequences of new agricultural technology. It is also incumbent upon them to point out the kind of measures that are necessary: a) to ensure that the beneficial effects of new technologies become available to the largest possible number of farmers and, b) to mitigate the potential dysfunctional effects for particular (poorer) groups in the rural community. In order to do this, they must be involved as early as possible in gathering information on the specific characteristics of the new varieties or technologies being developed. It is otherwise difficult to ensure that measures proposed for accomodation will reach the administration in time for adequate or appropriate action to be taken, and is a good argument for placing the sociologist within the research station.

\section{Scout}

Another interesting role that the sociologist could perform, be it a difficult one, is that of scout. A thorough analysis of rural societies and the changes that they are undergoing and will undergo in the near future, could make it possible for sociologists to indicate to agricultural scientists what kind of characteristics new technologies or varieties should have for rural communities to face present or expected developments in an optimal way. This steering approach (van Dusseldorp, 1977) is a 
demanding task because it not only requires a thorough analysis of the present but it requires an ability and the courage to suggest what developments are likely to occur in the near future in agrarian societies. To estimate the 'principia media' (Mannheim, 1960) that might indicate future change, is a difficult task for the sociologist because so many uncertainties exist. Scouting the road ahead should start with broad-scale cultural mapping. Such a role can be performed equally well inside as outside agricultural research stations.

\section{Developer of group technologies}

This role is important in situations where cooperation between farmers is necessary for a successful implementation of new or adjusted production technologies, as for example, in new irrigation techniques or integrated pest management systems.

In a role like this the sociologists may not only play the part of accommodator but can also examine the existing patterns of cooperation in specific societies and explore the possibilities and limitations that might constrain cooperation. On the basis of this information they are in a position to advise on what is feasible and likely to be acceptable and what measures have to take place in the field of community development. Again such a function can be performed as well inside as outside research stations.

Analysers of the functioning of agricultural research institutes and the agricultural research process

Finally the sociologist could be asked to analyse the way in which agricultural research institutes function. The following issues might be a useful focus of study. 1. The communication patterns and decision making processes in and between the departments of a matrix organization where the scientists are located in departments and where the actual work is accomplished by task forces organized around a specific problem.

2. Relations between agricultural research institutes and their directors and funding agencies and the influence that various actors have on the policy making process of these institutes.

3. The communication pattern between the end users of agricultural research findings and the extension organizations and subject-matter specialists who are in contact with them.

4. Communication between the various disciplines and the formal or informal mechanisms for achieving this.

This last role is completely different from the roles discussed earlier which were all, more or less, a part of the research process, if not a part of the research organization. This last function places them as outsiders looking in on the research institutes and the research process. It seems unwise to combine this role with the other nine roles that sociologists might perform, the main reason being that it is difficult, if not impossible, to function as an outside observer and evaluator and at the same time be treated as a trusted member of the staff of the institute; a trust that is abso- 
lutely necessary to perform the other functions effectively. It would seem advisable, therefore, for the sociologist performing this function to be located outside the agricultural research station.

\section{Observations and conclusions}

That sociological knowledge and expertise is important for agricultural research and for the implementation of its results is acknowledged, and the need for their involvement in the agricultural research process, as argued above, is, though sometimes reluctantly, accepted. It is therefore surprising that so few sociologists are actually working in agricultural research stations. There are various reasons for their small number and the weak positions they occupy in such institutes. Some of these reasons are mentioned below.

- It is not always necessary for them to be located in agricultural research stations, and sometimes they can perform their role more effectively when located outside. For a summarized overview see Table 1. In the past their functions have not always been clearly identified and distinguished and this had led to misunderstanding and confusion.

- Sociological knowledge is frequently seen to be, or is, experienced as common or ordinary knowledge (van Dusseldorp, 1989; Lindblom \& Cohen, 1979), that every person with common sense can produce.

- The fact that sociologists might question the social relevance of agricultural research findings means that they are not always acceptable to the management of research institutes, especially for reasons pertaining to the difficulty in obtaining financial support.

- Sociologists working in agricultural research may have difficulty in integrating their qualitative findings with the findings of other disciplines. The complexity of cooperation between disciplines with completely different cultures is often underestimated and sociologists and other scientists in agricultural research stations often have only limited training and experience in communicating with each other.

- It is often assumed that economists can provide the necessary sociological information because they are 'social scientists'. It also happens that economists in agricultural research stations often perceive the work of sociologists as an intrusion into their domain, although the contributions made by sociologists and economists are different with sociology placing more of an emphasis on:

a. Translating farmers' attitudes and knowledge into propositions for further research; their field diagnostic tools are more developed in this respect.

b. Qualitative data gathering methods which are, on the whole, more developed in sociology and anthropology, providing a valid complement to the quantitative approaches available to economists.

c. Institutional and social environment analysis, allowing, for example, the identification of communication barriers among the different partners in agricultural development.

Although we here make a case for sociology, we are aware that the dividing lines cannot be drawn absolutely. Sociologists and economists overlap in their activities 
in certain fields. Moreover we have found ample indications of mutual distrust and mistaken preconceptions between the two disciplines and would not want to contribute to this.

- The management of agricultural research institutes prefer to remain within the context of the 'neutral' technical discipline and fear that the inclusion of sociology could lead to outcomes with political implications.

- The budgets for agricultural research in developing countries are often so limited, that even persons from disciplines crucial to the technological field cannot be appointed. In such situations one cannot expect to find a great willingness among the technologically oriented communities in agricultural research stations to make room for sociologists.

- It is not surprising that in developing countries, when discussing interdisciplinary approaches such as, for example, farming systems research, one of the critical remarks heard is that such an approach is too costly for national research stations. - Sociologists themselves, for several reasons, among them the following, have only limited interest in working in agricultural research stations:

a. Good sociologists are not very interested in working in agricultural research stations where their main function is to generate knowledge for action, while the creation of knowledge for understanding (Scott and Shore, 1979) gives higher prestige. b. Sociologists who remain too long in the diaspora, miss the critical evaluation of their colleagues and are afraid to loose contact with the main stream of developments in their own science. There is little control or critical feedback on the quality of their sociological research.

The crucial importance of agricultural research for economic development and for the provision of food for a rapidly increasing third world population, is evident. In the last decades it has also become obvious that the fruits of such research can have a profound impact on rural societies and their environments. 'Agricultural development which emphasizes production over social concerns may tend to exacerbate existing social problems, and accelerate changes to the point that existing social compensation mechanisms are insufficient to prevent breakdowns in the social and economic order' (Wallace \& Jones, 1986).

It is therefore vital for the social sciences to be given and to take a more responsible position in agricultural research. Their role in farming systems research (FSR) was important but there are several indications that the fashionability of FSR is waning. Sociologists have also been important in developing adaptive agricultural research (AAR). However, considerable simplifications are necessary in the present expensive and area specific methodology before it becomes an efficient and economical tool for agricultural development in the third world. But no matter how important the role of sociologists in this section of adaptive agricultural research has been, agricultural research institutes are likely to remain important fountainheads for new technology in the future, and sociology must therefore be given a more secure footing in the agricultural research institutes themselves. Taking into account the problems mentioned earlier, this is certainly not a simple affair and several measures are needed to accelerate the process.

First, the education of agricultural scientists and sociologists through regular 
universities programmes, (which need not affect the quality of training in their own discipline) and post-graduate courses and in-service training should prepare them better for interdisciplinary work.

Second, a more thorough analysis is needed as to what interdisciplinary research really means. At present there is not enough insight into the complexity of this type of research which often leads to amateurism and misunderstanding.

Third, past attempts by several of the international agricultural research institutes to bring in single sociologists, on a temporary basis, should be carefully evaluated. To date this has had only limited success. It is worthwhile considering the idea of placing sociologists in agricultural research stations on long term detachment from their own sociological research institutes with whom they can maintain collaborative links. This makes the contribution of sociologists less dependent on their personal characteristics and provides them with backup and critical feedback.

Fourth, more attention should be given in the contribution sociologists can make through their work outside agricultural research institutes. They could in particularly contribute by translating the sociological knowledge already available into a form that is useful for agricultural research.

Finally, a note of caution. Sociology can certainly play an important part in providing agricultural technology that is better adapted to the social context. It does not mean, however, that they can solve all the social problems pertaining to the field. But to make a satisfactory job of it, sociologists need to be involved from the very beginning and must be given the same amount of time and weight as the other disciplines. To bring sociologists in at the very end of the research process, or to allow them only a temporary seat in the agricultural research institute, is only window dressing and will not lead to substantial results.

\section{References}

Box, L., 1988a. Experimenting cultivators: A method for adaptive agricultural research. Sociologia Ruralis 28 (1): $62-75$.

Box, L., 1988b. Making technology work for small scale farming: The VOTEX ricefan thresher's introduction in 60 countries. International Agricultural Centre, Wageningen, $6 \mathrm{pp}$..

Box, L., 1989. Knowledge, networks and cultivators: cassava in the Dominican Republic. In: N. Long et al. (Eds). Encounters at the interface: A perspective on social discontinuities in rural development, p. 165-182. Wageningen Studies in Sociology 27.

Brokenshaw, D., D. M. Warren \& O. Werner (Eds), 1980. Indigenous knowledge systems and development. University Press of America, New York, 460 pp.

Chambers, R., 1983. Rural development: putting the last first. Longman, Harlow, $246 \mathrm{pp.}$

Doorman, F., 1989. The use of social science methods in agricultural research: The case of late transplanting of rice in the Dominican Republic. Netherlands Journal of Agricultural Science 42: 97-105.

Dusseldorp, D. B. W. M. van, 1977. Some thoughts on the role of social sciences in the agricultural research centers in developing countries Netherlands Journal of Agricultural Science 25: 213-225.

Dusseldorp, D. B. W. M. van, 1989. Scientific sociological knowledge and its usefulness for the planned development process: Its potentials and limitations. In: Bhagwan Dahiya (Ed.), Theoretical Foundations of Development Planning. Vol. 1. Concept Publishing Company, India.

Feder, E., 1983. Perverse development. Foundation for Nationalist Studies. Quezon City, Philippines, $324 \mathrm{pp}$.

Finsterbusch, K. \& C. P. Wolf, 1981. Methodology of social impact assessment. Hutchinson Ross Publishing Company, Stroudsburg, Pennsylvania, 399 pp. 
Horton, D. E., 1984. Social scientists in agricultural research. International Development Centre, Ottawa, $67 \mathrm{pp}$.

Jones, J. R. and B. J. Wallace (Eds), 1986. Social sciences and farming systems research; methodological perspectives on agricultural development. Westview Press, London, $285 \mathrm{pp}$.

Kruiter, A., 1988. De junior partner. Sociologen in landbouwkundig onderzoek (In Dutch). Dept of Rural Sociology for the Tropics and Subtropics, Wageningen Agricultural University, $62 \mathrm{pp}$.

Lindblom, Ch. \& D. K. Cohen, 1979. Usable knowledge. Social sciences and social problem solving. Yale University Press, London, $129 \mathrm{pp}$.

Mannheim, K., 1960. Man and society in an age of reconstruction. Routledge and Kegan Paul Ltd, London, 469 pp.

Maxwell, S., 1986. The role of case studies in farming systems research. Agricultural Administration 21: 147-180.

Mellor, J. W. and R. Ahmed, 1988. Agricultural price policy for developing countries. Report No. 8. International Food Policy Research Institute, Washington, 4 pp.

Polak, A. \& L. Acena, 1985. Does growing modern varieties expel women from harvesting rice? International Rice Research Institute, Los Baños/Wageningen Agricultural University, 13 pp.

Polak, A., 1986. Social anthropological/sociological contributions to farmer oriented agricultural research: Outline of an approach. IRRI, Los Baños, Wageningen Agricultural University/KIT, Amsterdam, $99 \mathrm{pp}$.

Rhoades, R. E., 1984. Breaking new ground. International Potato Centre, Lima, 71 pp.

Ruttan, V. W., 1982. Agricultural research policy. University of Minnesota Press, Minneapolis, $369 \mathrm{pp}$.

Schlippe, P. de, 1956. Shifting cultivation in Africa, the Zande system of agricultural. Routledge and Kegan Paul, London, $304 \mathrm{pp}$.

Scott, R. A. \& A. R. Shore, 1979. Why sociology does not apply: A study of the use of sociology in public policy. Elsevier, New York, $265 \mathrm{pp}$.

Sutherland, A., 1987. Sociology in farming systems research. Agricultural Administration Unit Occasional Unit, Paper 6. Overseas Development Institute, London, $64 \mathrm{pp}$.

Technical Advisory Committee of the Consultative Group on International Agricultural Research, 1989. Sustainable agricultural production: implications for agricultural research. Research and Technology, Paper 4. FAO, Rome.

Wallace, B. J. \& J. R. Jones, 1986. Social science in FSR: Conclusions and future directions. In: J. R. Jones \& B. J. Wallace (Eds), Social sciences and farming systems research, p. 263-280.

Webb, E. J., D. T. Campbell, R. D. Schwartz \& L. Sechrest, 1966. Unobtrusive methods. Non reactive research in social sciences. Rand Mc. Nally College Publishing Company, Chicago, 225 pp. 